\title{
Reaching Resisters in a Teaching Assistant Training Program
}

\author{
Carolyn I. Brown, PhD \\ Writing Center and Plagiarism Prevention Program Coordinator \\ Webster University
}

In the past decade, there has been limited longitudinal qualitative research

examining the effects of training programs on graduate students' teaching performance. One gap in this research is a discussion of Teaching Assistants (TAs) who resist such programs and an examination of strategies for overcoming this resistance. This action research study attempts to fill that gap by evaluating the relationship between TAs' participation in one university's Certificate in University

Teaching (CUT) program and their resistance to its pedagogical strategies. The study defines the types of resistance and analyzes the reasons behind it. Findings address ways to more effectively reach resisting TAs and improve our own teaching practices.

In the past decade, there has been limited longitudinal qualitative research examining the effects of training programs on American graduate students' teaching performance (Park, 2004). Previous research focused on developing graduate courses on teaching in college/university environments (Ebest, 2005), identifying the need for TA training programs and program design (Lewis, 2002), and assessing the effectiveness of such programs (Davis \& Kring, 2001; Speer, Gutmann, \& Murphy, 2005), while the last 15 years have seen a marked increase in efforts to develop teaching excellence and student engagement in higher education (Abbott, Wulff, \& Szego, 1989; Gaff, Pruitt-Logan, Sims, \& Denecke, 2003).

One gap in this research is a discussion of Teaching Assistants (TAs) who resist such programs and an examination of strategies for overcoming this resistance. This research is part of a four-year longitudinal study that analyzes the effectiveness of one Midwest public land grant university's Certificate in University Teaching program (CUT) and unpacks graduate teaching assistants' classroom experiences. This part of the study defines the various types of resistance and analyzes the reasons behind it, focusing specifically on the following questions: What differentiated resisters from the rest of the CUT participants? Why did these students appear to resist and reject CUT principles? What role did the TA coordinators play in this resistance? Findings address ways to more effectively reach resisting TAs and improve our own teaching practices.

\section{Literature Review}

One of the challenges of training TAs is their varied teaching experience. In any given group, some may have teaching experience at the elementary, secondary or community college levels; some may have no teaching experience; and some may have had TA training during their M.A. program. "Not only do TAs enter at different levels, but, obviously, they grow at different rates in different dimensions" (Nyquist \& Sprague, 1998, p. 84). As with any developmental stage, those described above do not necessarily occur linearly. More importantly, as the authors note, growth and development are never finished. TAs benefit most from supervisors who are able to adapt as TAs develop, providing more supervisory support in the beginning stage and scaling back as TAs mature (Nyquist \& Sprague, 1998; Wulff, Austin, Nyquist, \& Sprague, 2001).

Keeping these developmental stages in mind, Nyquist, Abbott \& Wulff (1989) argue that TA training should focus on multiple dimensions of the TA experience and on the interrelatedness of those dimensions. The dimensions that the authors refer to include the needs and characteristics of the TAs themselves, the relationships that TAs have with other TAs, the demands of their students, and the 
expectations of supervisors, administrators, and instructional developers. Korpan (2014) suggests the model of workplace learning over the more traditional apprenticeship model that "provides a more holistic approach to work and learning" (p. 2).

In her study of composition graduate students' introduction to action research, Ruth Ray (1993) argues that students may resist new methods of teaching and research for rhetorical, pedagogical, or epistemological reasons. Students who resist for pedagogical reasons often question and challenge new teaching theories in the university classroom, while those who resist for rhetorical reasons do not believe that constructivist teaching strategies and active learning activities are appropriate in the academic classroom. Students who resist for epistemological reasons hold divergent beliefs about how knowledge is constructed and disseminated. The TAs in the resistance group demonstrated one or more of these areas of resistance to the CUT program.

A fourth type of resistance-oppositional-was demonstrated by two TAs in the low resister group. Henry Giroux (1983) argues that the category of opposition can be political: "Some acts of resistance reveal quite visibly their radical potential, while others are rather ambiguous; still others may reveal nothing more than an affinity to the logic of domination and destruction" (p. 109). Shor (1992) adds that oppositional students' behavior is a "reflexive resistance to authority" ( $p$. 138). Students internalize this resistance and "take their sabotaging skills wherever they go" (p. 139). The oppositional TAs in this section demonstrated poor attitudes and rejected both positive feedback and constructive criticism for no particular reason.

\section{Method}

Data sources included the following: intake and exit interviews, teaching observations, program observations, teaching logs, and workshop evaluations.

In this four-year study, I engaged in recursive cycles of observation-examining TAs' workshop participation and teaching performance; reflection-considering TAs' teaching and learning processes and performance; and action-seeking to improve my role in the CUT program as instructor, supervisor, and mentor. I also examined TA outcomes and evaluated my actions for outcome effectiveness. Changes in my approach to participants and alterations in curriculum were informed by the cyclical nature of the action research process. Simultaneously, TAs were engaged in their own recursive cycles of: observation-watching dynamic faculty teach across the curriculum; reflection-contemplating faculty teaching strategies as well as their own; action-changing their teaching performance based on feedback and reflections; and evaluation-assessing the effectiveness of their actions in their teaching logs. This recursive cycle allowed TAs the opportunity not

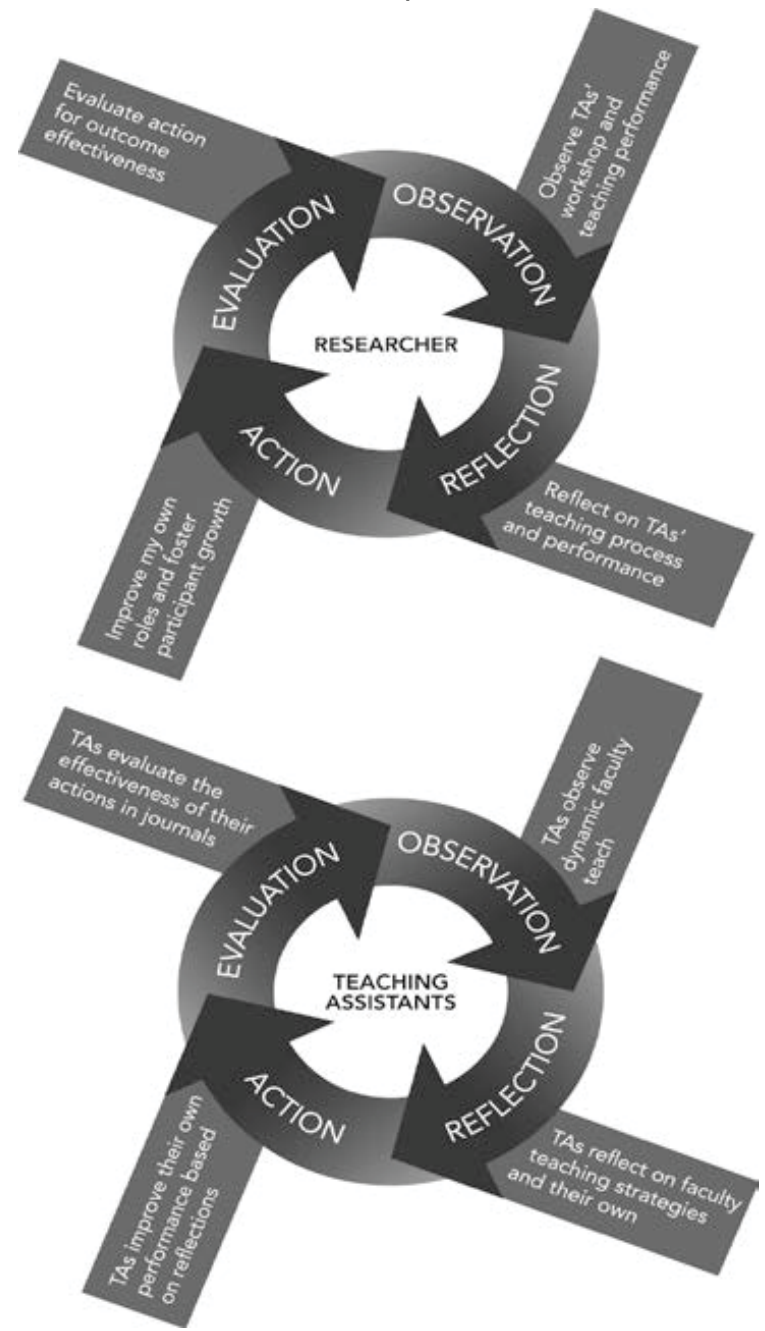

Figure 1. Action research study cycles of researcher and teaching assistants. 
only to strengthen their metacognitive skills, but also to develop a sense of selfefficacy as they began to understand their teaching. I met with study participants informally biweekly throughout the semester to share observations and listen to their ideas and concerns.

\section{The CUT Curriculum}

It is important to make clear that participation in the CUT program is voluntary for teaching assistants, though in order to receive the university certificate, all of the requirements of the program must be met. At the time of this study, CUT was comprised of four face-to-face units: Unit 1, Teaching for Learning in the University, which guided graduate students to promote active and meaningful learning in college classrooms and develop college students' critical thinking skills; Unit 2, Preparing for University Teaching, which required participants to expand their pedagogical knowledge of learning theory and practical classroom application; Unit 3, the Teaching Practicum, which monitored students' teaching, required reflective teaching logs, and provided regular feedback; and Unit 4, Professional Development, which focused on developing job talks, presenting at conferences, and preparing for publication. This study focused on behaviors in Units 1-3. Although this was a four-year study, teaching assistants generally completed this program within two years, so participants changed over time.

\section{Sample and Data Sources}

Forty TAs participated in various phases of the total research over nine semesters with IRB approval. Nine TAs comprised the resister focus of this portion of the study. Research participants represented the following fields: Political Science, Philosophy, History, Sociology, Biology, Education, English, Business, Communication, Psychology, Math, Gender Studies, and Nursing. Approximately half of the participants were doctoral candidates $(n=20)$; the others were pursuing their M.A. Of those who responded to the demographic data survey, 11 were males and 18 were female. The age range of the sample was $21-55+$ years old with the majority under 30 years. Twenty-one participants identified as Caucasian; five as African-American; five as Asian; one as Hispanic; and one as multiracial. Forty seven percent of the TAs enrolled in the CUT program over nine semesters had no prior teaching experience and 20 percent had one semester, while 55 percent had no teacher training. Fifty two percent were responsible for teaching one section of a course; 34 percent taught two or more sections. Eighty seven percent were planning a career in teaching and/or academia; nine percent were not; and three percent were undecided.

I worked with three levels of participants. Level 3 (L3), those who participated most in my study, included nine TAs in the Teaching Practicum; they were interviewed at the beginning and the end of their Practicum experience. Level 2 (L2), consisted of 14 participants whose teaching logs and teaching performance were evaluated, but they were not interviewed. Level 1 (L1) included all of the participants who attended CUT Units 1, 2, and 4, but who neither took the Practicum nor participated in personal interviews. This latter group varied per workshop and unit; therefore, attendance was inconsistent because participants could miss one (out of eight) workshop in Units 1 and 2 without penalty. Overall, approximately 17 additional graduate students (some TAs; some not) participated in L1. The data collected from this group included field notes and workshop evaluations; however, because they did not participate in the Teaching Practicum, I did not interview them. 
Table 1

Data Collection Sources and Procedures

\begin{tabular}{|c|c|}
\hline Sources & Procedures \\
\hline $\begin{array}{l}\text { Interviews ( } L 3 \text { ) } \\
\text { A total of } 18 \text { interviews were } \\
\text { conducted ( } 9 \text { participants } \times 2 \\
\text { interviews each) }\end{array}$ & $\begin{array}{l}\text { Semi-structured, conducted at the } \\
\text { beginning and end of the CUT } \\
\text { program; participants were audio } \\
\text { taped for transcription and coding }\end{array}$ \\
\hline Program Observations (L1, L2, L3) & $\begin{array}{l}\text { Field notes taken at every session of } \\
\text { CUT Units } 1,2 \text {, and } 4\end{array}$ \\
\hline Teaching Observations (L2, L3) & $\begin{array}{l}\text { Participants were observed three times } \\
\text { during a semester for a class period } \\
\text { using an observation protocol and then } \\
\text { given written and verbal feedback at a } \\
\text { conference following each teaching } \\
\text { session }\end{array}$ \\
\hline Document Collection (L2, L3) & $\begin{array}{l}\text { Participants submitted course syllabi } \\
\text { and assignments for evaluation } \\
\text { throughout study }\end{array}$ \\
\hline $\begin{array}{l}\text { Teaching Logs (L2, L3) } \\
\text { (A total of } 15 \text { entries for fall } \\
\text { and spring semesters; } 8 \text { for } \\
\text { summer semesters) }\end{array}$ & $\begin{array}{l}\text { Participants submitted their weekly } \\
\text { teaching journals written during the } \\
\text { Unit } 3 \text { Practicum for evaluation }\end{array}$ \\
\hline Participant Evaluations (L1, L2, L3) & $\begin{array}{l}\text { Evaluations were distributed to } \\
\text { participants at the end of each two- } \\
\text { hour workshop for all units }\end{array}$ \\
\hline
\end{tabular}

\section{Results}

Interview transcripts from participants were examined through narrative analysis (Bruner, 1991) and grounded theory using open coding (Glaser \& Strauss, 1967). Narrative analysis was used to interpret problem solving, conflict, and interpersonal relationships of the CUT participants as they experienced what it meant to become a teacher. Throughout the course of this study, I assumed multiple roles in the CUT program: researcher, teacher, supervisor, and mentor. I discovered that at times these roles somewhat conflicted, particularly when I simultaneously supervised the Practicum students and conducted research. As a supervisor, I was admittedly disappointed when participants did not perform as well as I had hoped in the classroom. With the resister group, especially, I became frustrated at their unwillingness to take my pedagogical advice. As a researcher, having these subjective feelings added layers to the analysis.

In the following sections, I illustrate the students' behaviors as pedagogical, rhetorical, epistemological, and oppositional resisters. As my analysis demonstrates, resistance could not and should not be confined to a single category. All names used in this study are pseudonyms to protect participant identity.

\section{Struggle in Resisters}

Pedagogical, rhetorical, and epistemological resistance. Matt was a TA in Sociology. In the CUT workshops, he seemed bored; when called on for his ideas, he declined to contribute to group exercises. Matt's teaching logs-which were supposed to focus on his professor's teaching methods when he [Matt] was not teaching-were undeveloped and unfocused. He failed to comment on what he 
would do differently if he were teaching the class; instead, he blamed the students for failing to learn and engage. During debriefing sessions following his teaching observations, I thought I was clear in relaying my concern that he should use CUT strategies and believed that Matt was amenable. Yet the very next week, instead of discussing his teaching session or his professor's, Matt wrote the following in his teaching log:

As the semester reaches mid-term I am stunned by student 'sign-of-life' postings within the course weekly discussion board forums. Questions are being asked over content that was presented in-class during weeks 1-3. Formal clarifying retorts to those student comments are met with a plethora of logical fallacies. It is quite depressing to my own teaching motivation when students fail to consider the preponderance of available empirical data demonstrating support for a particular stance on a controversial issue. I expect diversity in the classroom, but I also expect logical, objective examination of social phenomena that draws from preexisting data sets and sociological theories.

I noted that Matt had slipped to me that his students were "not smart" because their perspectives differed from his. He did not consider that his didactic teaching style, as well as his professor's, may have contributed to their students' performances. Further, by referring to the perceived lack of student motivation at length in every one of his journals, Matt avoided reflecting on the teaching environment he either observed or was a part of each class period.

When he failed to practice active learning strategies, I saw Matt as a singularly teacher-centered instructor, for that is where his comfort zone was. In other words, he was a pedagogical resister based on the strategies and holistic teachings of the CUT program. According to Ray (1993), pedagogical resisters maintain a teacher-centered classroom because they believe that students are either unmotivated or not intellectual enough. In Empowering Education, I ra Shor (1992) refers to the classroom's "alien culture" (p. 138) which resisters often feel prevents them from being noticed or heard. Given the emphasis on student engagement, the CUT program was alien to what Matt experienced in his own classroom as a student and in watching his supervising professor. Matt could also be considered an epistemological resister because he rejected educational psychology theories pertaining to learning and motivation. I witnessed Matt's resistance at every CUT workshop, for even though he did not comply with the teaching strategies offered, he complied with the program requirement of attending Friday sessions regularly.

Danny, also a Sociology major, claimed he found little value in most of the CUT program, although he did find his teaching experiences to be positive. Yet on the occasions that I observed Danny teach, he used few active learning elements and relied mostly on lecture. In his teaching logs, his negative attitude was difficult to ignore and even more difficult to influence. Danny admitted "he often [felt] bored in any learning environment," so I was challenged to understand why he would remain in the CUT program and surprised that he planned to continue his education at the doctoral level. Danny was a pedagogical resister because he did not believe in the teaching strategies the program offered; he was a rhetorical resister because he did not think anything other than lecture was appropriate for the college classroom. In sum, Danny's pedagogical and rhetorical resistance contributed to his overall dissatisfaction with the CUT program and resulted in his classification as a low implementer of active learning strategies.

Eric was a master's student in History; his thesis was so impressive it was accepted for publication. Clearly, Eric was a serious student. At the CUT workshops he sat alone and had to be coaxed to work with his peers during small group activities. Based on our conversations, I knew that Eric had struggled with a difficult personal and academic past, which may have contributed to his defensive 
attitude. But whereas Eric was passively resistant in CUT Units 1 and 2, he was actively resistant in the Practicum. As a teaching assistant, Eric was the discussion leader for an introductory History course and worked with a professor in his department who led the lecture. So even though Eric formulated his teaching logs into four basic questions-What were the day's goals and strategies? What worked well? What didn't? What would you do differently next time?-his responses were terse. Although he discussed what he did in class, he did not reflect on his teaching.

I hypothesized that there were several reasons why Eric was a resister. First, he preferred working alone and resisted peer response, declaring it intrusive and unnecessary. This mindset translated into the classroom-he would rather speak authoritatively to his students than work with them. Another contributing factor was his field-History is most often taught in a traditional lecture format, and it is doubtful that Eric had witnessed other types of pedagogical approaches from his professors. Most likely CUT's emphasis on de-centered teaching curriculum was new to Eric, so it was easier for him to resist than be uncomfortable trying to enact them in the classroom. Further, at the time he took the Practicum, Eric was focused on completing his master's thesis and applying for doctoral programs. Most likely, he wanted to please his professor and did not want to risk using teaching methods that he perceived to be out of his field's norm, if not inferior.

Oppositional resistance. Whereas Matt, Danny, and Eric were pedagogical, rhetorical, and epistemological resisters, Lesley could be classified as oppositional. She was distracted in CUT workshops and spent her time during group activities socializing with peers or misdirecting them away from relevant discussion, behaviors which Shor (1992) describes as resisting authority. On many occasions I had to ask Lesley to focus on the task at hand; likewise, I wrote in my field notes that Lesley did not appear to take the workshops seriously, for she regularly arrived late, rarely paid attention (e.g., surfing the internet and reading email), refused to participate, and generally exhibited a lack of respect for her peers and for the CUT program director. Shor (1992) calls this behavior "getting by," an oppositional strategy characterized by defensive and negative behavior used to manipulate teachers (p. 138).

Lesley's lack of professionalism carried over into her teaching. I visited her classroom separately on two occasions and once with my colleague. Lesley's class (ironically, Educational Psychology) was taught in a computer classroom, which meant the students sat in fixed rows with a computer in front of them. Each time I observed, I saw the same environment: approximately the first 15 minutes of class consisted of small talk with no instruction; worse, there was little evidence of preparation; limited control of the classroom (students were shopping online, visiting social network sites, doing homework); and no instructional objectives. In sum, Lesley's behavior mirrored that of her students-and vice versa. During my debriefing sessions following her teaching observations, Lesley declared she was committed to positive changes in the classroom, but could not articulate specifics on what strategies she would use, and I found no improvements in subsequent visits. As a result, Lesley did not receive a certificate of completion for the Practicum and left the CUT program before completing the final unit.

Like Lesley, Elliott was oppositional. Elliott was a Philosophy TA and taught medical ethics during the semester I observed. My colleague conducted the first observation three weeks into the semester, when she noted that

the classroom climate was a little reserved and the mix of teacher talk and student talk was 75/25. I didn't see any active learning strategies. Worse, he used inappropriate examples including revealing a family member's sexually transmitted disease out of context, when a more suitable example, with as much if not more relevance could have been used. 
My colleague discussed her concerns with Elliott in their debriefing, explaining that his comments could be problematic and advising him to be more careful in his examples. I observed Elliott one month later for his second visit. He arrived at least five minutes late and spent most of the class period off topic with little to no student involvement. While I noted that he seemed confident and appeared comfortable in front of the class, in a medical ethics example, he gave more revealing information about a recent physical exam he had. Not only were these comments inappropriate, they also suggested a misuse of authority. Though the subject matter of the course was medical ethics which allowed for sensitive information to be discussed, Elliott's choices clearly made students uncomfortable, as whole class discussion ceased.

I discussed Elliott's comments with my colleague, and then I met with him to review his conduct. It is important to note that the CUT program is voluntary, and there is an agreement with the TAs that their performance is not reported to their superiors unless I witness highly egregious behavior. Otherwise, it is the responsibility of 'TAs' supervising professors and/or department chairs to monitor them. My role is to serve as an advocate for the TAs and to help them make pedagogical and classroom management choices that contribute to an effective classroom. But Elliott's comments, while out of place and unprofessional, were just one part of his resistance - he also stopped writing teaching logs prior to my visit, and shortly after our discussion, dropped out of the CUT program.

Elliott is another example of oppositional resistance. I suspected he was a resister given his behavior both in and out of the classroom. At the pre-semester Graduate Student Professional Development Conference and during every CUT workshop, Elliott sought attention via inappropriate comments. Needless to say, he did not receive an abundance of positive response from either my colleague or me following his teaching observations, so he may have felt marginalized. It is important to note that he and Lesley sat next to each other at CUT workshops and were almost always off task together, so perhaps they both felt like outsiders. According to Shor (1992), Elliott and Lesley established a "peer group identity based on their prestige as rebels"-though their peers were not impressed (p. 139).

Rhetorical resistance: Rule-governed cultures. TAs Rena and Beth shared similar characteristics: they were both pursuing their MAs in English, they taught the same courses, and they came from rule-governed cultures. These cultures, which were patriarchal and did not focus on the development of a female as an intellectual, appeared to affect their roles in the classroom. Rena was raised in a highly religious community. And while modern religious women have more educational opportunities than their foremothers, in Rena's culture, women are still assigned traditional gender roles of wife and mother first. Beth was AsianAmerican. Joel Spring (2006) notes that "in Confucian tradition, the teacher is an extension of the parent. Teachers are given a great deal of respect and status. Students are expected to obey and respect their teachers in the same ways they respect their parents" (p. 155). My observations confirmed that Beth held this belief.

In spite of the intensive pedagogical training they received in their home department and in the CUT program, Rena and Beth were clearly teacher-centered in their approach. Both women lectured from the front of the classroom, and neither drew on any of the CUT teaching strategies. Rena appeared more open than Beth in discussing ways to improve her teaching; however, she resisted making any changes in the classroom. Each woman discussed her cultural influences with me during our teaching debriefings and attributed her teaching style in part to environment. I observed each of them during the Practicum, and noted that they were rather inaccessible as instructors and somewhat distant from their students. In a class of which one quarter were minority students, Beth made disparaging remarks about rampant illiteracy in the African-American community; in her computer classroom, Rena lectured on grammar and mechanics but did not follow 
through with practical applications. My colleague corroborated my observations during her own visits.

It was not until the end of that semester when I compared Rena and Beth's backgrounds and teaching styles that I recognized similar patterns. Both women were rhetorical resisters, for they questioned the appropriateness of using CUT strategies in the classroom context. Because each woman still strongly identified with her own culture and because the values of those cultures were highly traditional and rule-governed, there appeared to be a transfer into the classroom. It is possible that Rena and Beth found value in CUT strategies; whether they applied them as new faculty is unclear.

\section{Discussion}

I had hoped that the resisters would engage in parallel cycles like their more successful peers; however, this group had difficulty not only with their teaching but also in achieving metacognition and self-awareness. In analyzing the findings, I looked closely at my own behavior toward the resisters. I realized that my professional and personal beliefs became increasingly blurred as I grew uneasy and frustrated with the students during the Practicum. I wanted the TAs to succeed and I attempted to give ... as their teaching logs continued to be indifferent, condemning, and tangential, and when my second and third observations showed little to no enactment of strategies, I felt deflated as a practitioner.

them specific strategies and encouragement in writing and during our debriefings. But as their teaching logs continued to be indifferent, condemning, and tangential, and when my second and third observations showed little to no enactment of strategies, I felt deflated as a practitioner. The action research cycle of observation, reflection, action, and evaluation was affected as I struggled to connect with them. While I remained professional even when some participants in this group became defensive, I had to consider that my frustration may have prevented me from approaching them differently. I admittedly had less patience for this group and at times likely entered their classrooms focusing more on what was wrong rather than what was working. Had I kept our expectations more neutral I might have identified some positive behaviors.

Obviously, it was difficult not to make assumptions about the participants over the course of this study and resist the temptation to oversimplify the reasons for their pedagogical choices and subsequent categorizations. Even as I carefully reviewed and coded the data, I wondered how and if my beliefs affected the participants and influenced their subsequent behavior. Certainly, my educational, pedagogical, and cultural background shaped my curricular choices as well as my expectations. Other participants, who had highly positive experiences, viewed me as a mentor, but those who had considerable difficulty with the program and those who left did not connect with me as a teacher or mentor; consequently, I cannot help but consider my role in the resisters' outcomes.

At the same time, the students' attitudes and beliefs informed their behaviors. In a five-year study of graduate composition TAs, Ebest (2005) concluded that the "resistant few were unable to overcome their resistance because constructivist pedagogy contradicted their personal constructs and threatened their sense of self-efficacy" ( $p$. 65). The term personal construct, developed by psychologist George Kelly (1955a, 1955b), represents a person's worldview. Personal construct is built on one's past experiences, relationships with others, thoughts and actions based on culture and environment. The more firmly rooted one's personal construct, the more difficult it is to change. In this study, personal construct serves as a lens through which the TAs viewed education, teaching, and their roles in the academic environment.

The resister group shared a narrow worldview of teaching. None of them were open to constructive criticism, although that was the primary purpose of the 
Practicum. Because of their personal constructs and (apparent) low sense of selfefficacy in the classroom, they demonstrated one or more of the following types of resistance: rhetorical, pedagogical, epistemological, or oppositional. The oppositional participants were the most difficult to work with because they did not take the CUT program seriously, as evidenced by their failure to complete it. CUT rarely has an attrition issue since it is voluntary, so I took their decisions personally. This group also appeared to benefit least from the program, yet from my perspective, they needed CUT the most. Consequently, focusing on this group is one of the most important ways to improve the CUT curriculum. How do we reach them? First, we must recognize our students' academic contexts:

1. Their prior teaching experiences;

2. The teaching models they observed;

3. Their disciplinary areas;

4. Their motivation (e.g., Psychology and Political Science required attendance, while other disciplines ranged in attitude from indifferent to hostile to the CUT program).

Second, it is important to note that the resisters did not learn how to reflect by the end of the Practicum either because they lacked the metacognitive skills, they needed more modeling, or they did not value reflection as part of the teaching process. Because this group displayed various levels and types of resistance, it is most difficult to understand their motivation for completing the CUT program. To address this issue, I suggest the following strategies.

\section{Build in More Opportunities for Reflection}

This decision has been addressed by Schon (1995) and Brookfield (1995) and builds on one of the pedagogical competencies proposed by Kalish et al. (2012) that graduate students should "learn to assess and improve their own teaching performance through critical reflection" (para. 10). To teach reflective strategies, a minimum of four reflections are required on the CUT workshops during both fall and spring semesters to be submitted in an electronic research log. More frequent opportunities for face-to-face reflection, including practicing listening and mirroring classroom experiences in dyads, and semi-structured small group dialogue built into workshop time will further prepare teaching assistants for critical thinking and understanding. In addition to preparing TAs for reflective practice during their teaching practicum, written journals with facilitator feedback have a number of benefits:

- Professionalism: they will inculcate in graduate students the habit of reflecting on their teaching and research (Austin \& McDaniels, 2006; Ferraro, 2000; Kane, Sandretto \& Heath, 2004).

- Accountability: the self-awareness entailed in reflection should draw attention to the value of practicing strategies introduced in the CUT workshops.

- Retention: critical reflection should positively impact TAs' teaching, which in turn may influence undergraduate retention (McAlpine \& Weston 2002; Osterman \& Kottkamp, 2004).

- Specificity: periodic reflections will provide details for TAs' Teaching Philosophy and map their grasp of pedagogical strategies when developing the reflective introduction to their teaching portfolios.

- Assessment: reflections will provide qualitative data to evaluate and revise the CUT curriculum. 


\section{New Directions}

Remind ourselves that contextual factors play a significant role in shaping TAs' personal constructs. Contextual factors-including learning style, modeling, personality, motivation, culture, attitude, engagement, workload, and freedom of choice-situate a community of practice and its individuals and give educators a way to unpack these influences in a more nuanced way. Acknowledging the various contributors to graduate students' learning and teaching process will help TA coordinators work with their program participants more effectively. TA coordinators need to practice what we preach: maintaining reflective logs, looking for patterns, and recognizing our own biases models this behavior for our students and allows us to be critically reflective practitioners.

Offer more opportunities to observe good teaching. Many participants in the resister group did not have professors in their own departments who practiced active learning in the classroom, so it is not surprising that they did not embrace CUT strategies. Consequently, my colleague and I have begun to identify professors in each discipline who model active learning strategies for TAs to observe. Moreover, offering opportunities for CUT participants to observe good teaching, especially in their own discipline, builds on the vicarious experience aspect of self-efficacy. Further, experienced TAs can serve as strong pedagogical models as there is less of a differential in status and power between peers (Long, Holberg, \& Taylor, 1996).

Expand mentoring opportunities. The CUT program offers a mentoring component in which participants are paired with a professor at an institution of their choice for a day, shadowing the professor in class and at professional activities. While this is certainly a positive experience, the short interaction does not allow for a more developed relationship to form. It is worthwhile to consider an e-mentoring program for CUT participants. This component would be especially beneficial for the resisters, who would have the opportunity to build a strong relationship with a professor in their field and provide an additional positive resource.

I ncrease lines of communication. One of the strategies faculty use with undergraduate students struggling in our courses is to hold individual conferences to ascertain why they are having difficulty. This time allows us to find ways to help the student with the course, to problem solve when necessary, and perhaps most importantly, to show students that we care about their learning and progress. So in addition to written responses to the teaching logs and post-observation debriefings, it would be beneficial for Practicum participants to meet with me more frequently. In the resister group, each participant was visibly uncomfortable and defensive during their debriefing session. Perhaps if we met before their first observation, these students would have a chance to express their fears and explain their philosophies. More importantly, we might listen more effectively, which could give the resisters a sense of agency and help participants work through and/or overcome their resistance.

Clearly, not every graduate student will embrace constructivist theory if it conflicts with his/her personal constructs. But keeping in mind that the main goal of TA training is to help graduate students become effective educators, TA developers can benefit from reflecting on how they function as teachers and mentors, for this will help them to model best teaching practices.

Realize that resistance can help empower transformative teaching. While working with this group certainly had its challenges, I was with them for a finite amount of time. Future studies may focus on teaching experiences and styles of former teaching assistants as they begin their first professional and academic positions to examine the possible impact their TA training program had on them. Admittedly, learning to teach effectively is an ongoing process; because I did not 
see immediate willingness to engage students from the resisters does not mean they did not learn from the CUT program.

Conversely, at the time of this study, I have revealed that I had some resistance in being open to the varying levels of preparedness of CUT teaching assistants. This experience has taught me that in reflecting on my own resistance in the process I have improved my own teaching and training methods for students. As a result, I am more cognizant of meeting students where they are.

\section{References}

Abbott, R. D., Wulff, D. H., \& Szego, C. K. (1989). Review of research on TA training. In J. D. Nyquist, R. D. Abbott, \& D. H. Wulff (Eds.), Teaching assistant training in the 1990s (pp. 111-124). San Francisco, CA: Jossey-Bass.

Austin, A. E., \& McDaniels, M. (2006). Preparing the professoriate of the future: Graduate student socialization for faculty roles. In J.C. Smart (Ed.), Higher education: Handbook of theory and research (Vol. XXI, pp. 397-456). Netherlands: Springer.

Brookfield, S. (1995). Becoming a critically reflective teacher. San Francisco, CA: Jossey-Bass.

Bruner, J. (1991). The narrative construction of reality. Critical Inquiry, 18(1), 1-21. Retrieved from http://criticalinquiry.uchicago.edu/

Davis, S., \& Kring, J. (2001). A model for training and evaluating graduate teaching assistants. College Student Journal, 45-51. Retrieved from http: //www. preparing-

faculty.org/model-GTAs.pdf

Ebest, S. B. (2005). Changing the way we teach: Writing and resistance in the training of teaching assistants. Carbondale, IL: Southern Illinois University Press.

Ferraro, J. M. (2000). Reflective practice and professional development. Retrieved from ERIC database. (ED449120)

Gaff, J. G., Pruitt-Logan, A. S., Sims, L. B., \& Denecke, D. D. (2003). Preparing future faculty in the humanities and social sciences: A guide for change. Washington, DC: Council of Graduate Schools and Association of American Colleges and Universities.
Giroux, H. A. (1983). Theory and resistance in education. South Hadley, MA: Bergin \& Garvey Publishers, Inc.

Glaser, B. G., \& Strauss, A. L. (1967). The discovery of grounded theory: Strategies for qualitative research. Chicago, IL: Aldine.

Kalish, A., Border, L., Chandler, E., Gilmore, J., Griffith, L., Hansen, S.,... Von Hoene, L. (2012, October 24). Designing a competency-based approach to graduate and professional student development. Presentation at the Professional and Organizational Development Network in Higher Education Annual Conference, Seattle, WA.

Kane, R., Sandretto, S., \& Heath, C. (2004). An investigation into excellent tertiary teaching: Emphasizing reflective practice. Higher Education, 47, 283-310. Retrieved from http://link.springer.com/ journal/ 10734

Kelly, G. (1955a). A theory of personality: The psychology of personal constructs. New York, NY: W.W. Norton.

Kelly, G.A. (1955b). The psychology of personal constructs, vol. 1: A theory of personality, vol. 2: Clinical diagnosis and psychotherapy. New York, NY: Norton.

Korpan, C. (2014). From teaching assistant (TA) training to workplace learning. Collected Essays on Teaching and Learning, 7(2), 1-8. Retrieved from http: //celt. uwindsor.ca/ojs/leddy/ index.php/CELT 
Lewis, K. G. (2002). When teaching assistants teach teaching assistants to teach: An historical view of a teacher preparation program. In B. P. Pytlik \& S. Liggett (Eds.), Preparing teachers of college writing: Histories, programs, theories, and practices (pp. 40-49). New York, NY: Oxford University Press.

Long, M. C., Holberg, J. H., \& Taylor, M. M. (1996). Beyond apprenticeship: Graduate students, professional development programs and the future(s) of English studies. WPA, 20:1/2, 66-78.

McAlpine, L., \& Weston C. (2002). Reflection: Issues related to improving professors' teaching and students' learning. In N. Hativa \& P. Goodyear (Eds.), Teacher thinking, beliefs and knowledge in higher education (pp. 5978). Netherlands: Kluwer.

Nyquist, J. D., Abbott, R. D., \& Wulff, D. H. (Eds.). (1989). Teaching Assistant training in the 1990s: New directions for teaching and learning. San Francisco, CA: Jossey-Bass.

Nyquist, J. D., \& Sprague, J. (1998). Thinking developmentally about TAs. In M. Marincovich, J. Prostko, \& F. Stout (Eds.), The professional development of graduate teaching assistants (pp. 6188). Bolton, MA: Anker Publishing Company.

Osterman, K. F., \& Kottkamp, R. B. (2004). Reflective practice for educators: Professional development to improve student learning. Thousand Oaks, CA: Corwin Press.
Park, C. (2004). The graduate teaching assistant (GTA): Lessons from North American experience. Teaching in Higher Education, 9, 349-361. Retrieved from http://www.tandfonline.com/ loi/cthe

Ray, R. E. (1993). The practice of theory: Teacher research in composition. Urbana, IL: National Council of Teachers of English.

Schon, D. A. (1995). The reflective practitioner: How professionals think in action. Ann Arbor, MI: The University of Michigan.

Shor, I. (1992). Empowering education. Chicago, IL: University of Chicago Press.

Speer, N., Gutmann, T., \& Murphy, T. J. (2005). Mathematics teaching assistant preparation and development. College Teaching, 53(2), 75-80. Retrieved from http://www.tandfonline.com/

loi/vcol20\#.VOTKzqROzEY

Spring, J. (2006). The intersection of cultures. New York, NY: Routledge.

Wulff, D. H., Austin, A., Nyquist, J., \& Sprague, J. (2001). The development of graduate students as teaching scholars: A four-year longitudinal study. In D. H. Wulff \& A. Austin (Eds.), Paths to the professoriate: Strategies for enriching the preparation of future faculty (pp. 4673). San Francisco, CA: Jossey-Bass.

Carolyn I. Brown, PhD, is the Writing Center and Plagiarism Prevention Coordinator at Webster University in St. Louis. She teaches in the areas of Education and English, including student teaching, instructional methods, and classroom management, as well as writing. Her research interests include faculty development in student engagement, teaching assistant training, and writing across the curriculum. 